\title{
Endoscopic alcohol injection therapy of giant gastric leiomyomas: An alternative method to surgery
}

\author{
Burhan Ozdil MD¹, Hikmet Akkiz MD ${ }^{1}$, Can Kece MD², Macit Sandikci MD ${ }^{1}$
}

\begin{abstract}
B Ozdil, H Akkiz, C Kece, M Sandikci. Endoscopic alcohol injection therapy of giant gastric leiomyomas: An alternative method to surgery. Can J Gastroenterol 2010;24(9):533-535.
\end{abstract}

Leiomyomas are the most common benign mesenchymal tumours of the upper gastrointestinal tract. They rarely cause symptoms when they are smaller than $5 \mathrm{~cm}$ in diameter. Observation with repeated endoscopies is recommended in asymptomatic patients with small lesions. Surgical resection remains the main therapy option for symptomatic and complicated patients. The treatment of esophageal leiomyoma has been enhanced by improvements in diagnostic and therapeutic endoscopic techniques; however, the same cannot be said for gastric leiomyoma management. The present article describes the management of two cases involving giant gastric leiomyomas that were successfully treated using endoscopic injection of alcohol. To the authors' knowledge, the present study is the first report of the treatment of such hemorrhagic gastric tumours using this alternative and low-cost technique. Endoscopic local ethanol injection may be the treatment of choice in carefully selected patients with hemorrhagic leiomyomas of the upper gastrointestinal tract.

Key Words: Alternative therapy; Endoscopic therapy; Gastric leiomyomas; Surgical therapy

T eiomyomas are the most common submucosal tumour of the upper gastrointestinal (GI) tract (1). The incidence of these rare tumours in the upper GI tract is $4 \%$ of all tumours of the esophagus and $1 \%$ of stomach tumours (2). Leiomyomas may be submucosal, intramural or subserosal. In autopsy studies (1-4), almost all GI leiomyomas were located in the muscularis propria. Usually they are solitary entities and rarely multiple. Pain and GI bleeding are common presenting symptoms. The preoperative diagnostic algorithm includes radiographic examination of the upper GI tract, endoscopic examination with biopsy, ultrasound examination and computed tomography (CT). Lesions reaching the muscularis propria are difficult to resect using standard endoscopic electrosurgical techniques. These interventions usually result in potentially serious complications such as perforation or hemorrhage. However, traditional open surgery and laparoscopic resection are more invasive. The treatment of large hemorrhagic gastric leiomyomas by endoscopic alcohol injection is considered to be a new method. In our clinic, two patients who presented with hemorrhage and had large gastric leiomyomas detected via endoscopic examination were treated successfully with this alternative method.

\section{Une thérapie par injection endoscopique d'alcool dans des léiomyomes gastriques géants : Une alternative à la chirurgie}

Les léiomyomes sont les tumeurs mésenchymateuses du tube œsogastroduodénal les plus courantes. Ils provoquent rarement des symptômes lorsqu'ils sont d'un diamètre inférieur à $5 \mathrm{~cm}$. L'observation et des endoscopies répétées sont recommandées chez les patients asymptomatiques ayant de petites lésions. La résection chirurgicale demeure la principale option thérapeutique chez les patients symptomatiques et complexes. Le traitement du léiomyome œsophagien a progressé grâce aux améliorations diagnostiques et aux techniques d'endoscopie thérapeutique, mais on ne peut pas faire le même constat pour la prise en charge du léiomyome gastrique. Le présent article décrit la prise en charge de deux cas mettant en cause des léiomyomes géants traités avec succès au moyen d'une injection endoscopique d'alcool. En autant que le sache l'auteur, la présente étude représente le premier compte rendu du traitement de ces tumeurs gastriques hémorragiques au moyen de cette technique peu coûteuse. L'injection endoscopique localisée d'éthanol pourrait être le traitement de choix chez des patients ayant un léiomyome hémorragique du tube œsogastroduodénal, s'ils sont sélectionnés avec soin.

\section{CASE PRESENTATIONS}

The patients, a 45-year-old man and a 56-year-old woman, were hospitalized due to upper GI bleeding. Endoscopic examination of the male patient revealed a $6 \mathrm{~cm} \times 9 \mathrm{~cm}$ submucosal mass and a smooth superficial mucosa, with several ulcers $5 \mathrm{~mm}$ to $10 \mathrm{~mm}$ in diameter at the gastric cardia. The female patient underwent endoscopy, which detected a $10 \mathrm{~cm} \times 10 \mathrm{~cm}$ mass at the small curvatura that essentially filled the stomach lumen, extending from the antrum to the corpus-cardia border, with ulcer and a clot above with a diameter of $7 \mathrm{~mm}$ to $8 \mathrm{~mm}$ (Figure 1A). There was no bleeding in either patient at the time of the alcohol injection interventions. Abdominal CT scans were performed on both patients, which revealed masses extending to the stomach lumen and having intact serosa. No bleeding was observed in the patients while they were on weekly proton pump inhibitor and antacid treatment. Endoscopy was repeated. Endoscopic biopsies of both masses indicated leiomyoma. Both patients gave their informed consent to undergo endoscopic alcohol injection therapy. In both cases, the injection treatments of $98 \%$ alcohol were administered in a single session. A total of $20 \mathrm{~mL}$ alcohol was administered in the male patient, and $30 \mathrm{~mL}$ alcohol was administered through the centre and

${ }^{1}$ Faculty of Medicine, Department of Gastroenterology, Cukurova University, Adana; ${ }^{2}$ Department of Gastroenterologic Surgery, Research Hospital, Trabzon, Turkey

Correspondence: Dr Burhan Ozdil, Department of Gastroenterology, Cukurova University, Yuregir, Adana, Turkey. Telephone 536-557-5806, fax 90-322-338-6068, e-mail burhanozdil@gmail.com

Received for publication November 24, 2009. Accepted February 8, 2010 

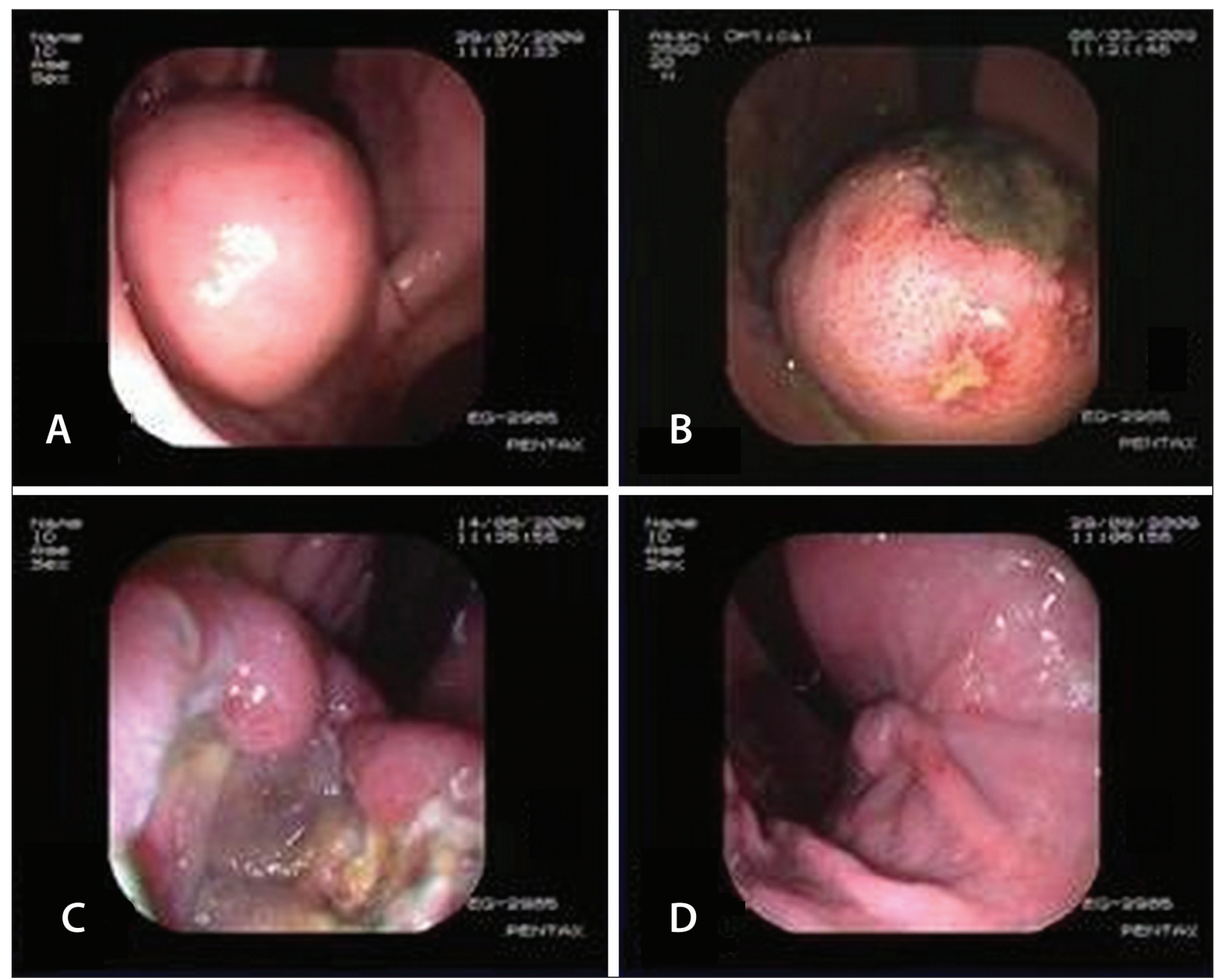

Figure 1) A Endoscopic appearance of the gastric leiomyoma in the 56-year-old female patient during the first examination. B The endoscopic appearance of the mass five days after alcohol treatment. An ulcer was observed on the surface of the mass. C Fifteen days after alcohol treatment, ulceration was seen on the entire mass. D Three months after alcohol treatment, the mass disappeared, with improvements in the observed ulcer

four quadrants of the tumour in the female patient. A standard $5 \mathrm{~mm}$ endoscopic sclerotherapy needle was used for injection. A control endoscopy was performed two weeks later. Deep ulcers, which developed at the alcohol injection sites, were observed in both patients (Figures $1 \mathrm{~B}$ and $1 \mathrm{C}$ ). However, the tumoral tissues in the vicinity of the injection sites were macroscopically normal. The same amount of alcohol was injected a second time. The patients were discharged after one week of monitoring. Three months later, endoscopic examination revealed no evidence of tumours. The ulcers were treated and the stomach mucosa had regained its normal anatomical structure (Figure 1D).

\section{DISCUSSION}

Leiomyoma is the most common upper GI submucosal tumour (1-5). Although malignant transformation is rare, and lesions less than $3 \mathrm{~cm}$ in diameter have been treated conservatively, some leiomyomas gradually increase in size and produce clinical symptoms such as hemorrhage, pain and obstruction $(6,7)$. In many patients, upper GI leiomyomas are usually asymptomatic; however, the presence of the lesion can be a psychological burden. For extremely large leiomyomas, endoscopic treatment is difficult. In symptomatic patients with larger tumours, conventional surgery is usually recommended (8).

Leiomyomas are traditionally treated via surgical intervention, with many recent reports (8-13) describing laparoscopic resection of these submucosal tumours. Although laparoscopy is considered to be minimally invasive, the endoscopic approach is even less invasive. Endoscopic snare resection of gastric submucosal lesions has been considered in a few reports, suggesting that endoscopic resection may be a favourable and advisable alternative to surgery. However, leiomyomas frequently arise in the muscularis propria, and endoscopic mucosal resection of submucosal lesions that are localized near the serosa or the adventitia is associated with particularly high risks. Therefore, meticulous patient selection is mandatory to avoid adverse major complications such as perforation and hemorrhage (14-19). 
Endoscopic procedures such as polypectomy and band ligation are difficult to use for lesions that are greater than $15 \mathrm{~mm}$ in diameter (20). The conventional endoscopic methods may require longer duration depending on the technique used as well as their associated risk. The localization, dimension and form of the tumour are important considerations for a successful intervention $(21,22)$. In our patients, endoscopic snare resection appeared to be unsuitable due to the size of the tumours. No method for the treatment of these large tumours has been reported in the literature. Therefore, we suggest endoscopic alcohol injection as an alternative treatment modality for the treatment of gastric leiomyomas. Tumours smaller in size would be amenable to snare resection. Because tumour size was decreased much more than expected after the first injection, a second injection was given. Complete treatment of the tumours was observed at the time of follow-up endoscopy.

Although endoscopic snarectomy is a frequently used method, alcohol injection treatment appears to be safer because it is not associated with a risk of acute perforation nor does it need to be applied to the entire tumour. The use of alcohol injection decreases tumoral mass by necrosing. We suggest that tumoral necrosis develops because the administered alcohol triggers an immunological reaction. To avoid the possibility of alcohol-induced necrosis and perforation of

\section{REFERENCES}

1. Postlethwait RW. Benign tumors and cysts of the esophagus. Surg Clin North Am 1983;63:925-31.

2. Wenger FA, Jacobi CA, Zieren HU. Diagnosis and therapy of leiomyoma of the upper gastrointestinal tract. Langenbecks Arch Chir 1996;381:221-4.

3. Postlethwait RW, Musser AW. Changes in the esophagus in 1,000 autopsy specimens. J Thorac Cardiovasc Surg 1974;68:953-6.

4. Takubo K, Nakagawa H, Tsuchiya S, Mitomo Y, Sasajima K, Shirota A. Seedling leiomyoma of the esophagus and esophagogastric junction zone. Hum Pathol 1981;12:1006-10.

5. Xu GQ, Zhang BL, Li YM, et al. Diagnostic value of endoscopic ultrasonography for gastrointestinal leiomyoma. World J Gastroenterol 2003;9:2088-91.

6. Hatch GF III, Wertheimer-Hatch L, Hatch KF, et al. Tumors of the esophagus. World J Surg 2000;24:401-11.

7. Bjork JT. Nonepithelial neoplasms of the stomach. Gastrointest Endosc 1981;23:162-3.

8. Dorais J, Marcon N. Endoscopic resection of gastrointestinal tumors: How far can the endoscopist go? Endoscopy 1997;29:192-5.

9. Wolfsohn DM, Savides TJ, Easter DW, Lyche KD. Laparoscopy assisted endoscopic removal of a stromal-cell tumor of the stomach. Endoscopy 1997;29:679-82.

10. Allam ME, Mehta D, Zelen J, Fogler R. Posterior wall gastric leiomyoma: Endoscopic tattooing facilitates laparoscopic resection. JSLS 1998;2:83-4.

11. Seelig MH, Hinder RA, Floch NR, et al. Endo-organ and laparoscopic management of gastric leiomyomas. Surg Laparosc Endosc 1999;9:78-81.

12. Yamashita Y, Maekawa T, Sakai T, Shirakusa T. Transgastrostomal endoscopic surgery for early gastric carcinoma and submucosal tumor. Surg Endosc 1999;13:361-4. a whole layer of the the stomach in both patients, deep injection of alcohol was not performed. It was observed at the time of follow-up endoscopy that while there was necrosis at the injection sites in the four quadrants of the tumour, no significant necrosis was observed in neighbouring regions. An intensive polymorphonuclear cellular infiltrate was observed in the biopsy samples obtained from healthy-appearing tissue (result of second biopsy) during the control endoscopy. Observations of follow-up biopsy samples taken three months later showed that the mucosa had healed completely, the masses had disappeared and the stomach mucosa had regained its normal anatomical structure.

In our opinion, another advantage of this method is the development of coagulation in vascular structures during the process as a result of the administered injection, which prevented bleeding. Thus, no bleeding was observed during or following the process in both cases. A patient with esophageal leiomyoma was treated successfully using endoscopic alcohol injection (23); however, the lesions in this case were smaller than $3 \mathrm{~cm}$ in size.

Alcohol injection may be a safe alternative to surgery for the treatment of large gastric leiomyomas. This method appears to be more applicable, much more effective, less invasive and more cost effective than surgery.

13. Hepworth CC, Menzies D, Motson RW. Minimally invasive surgery for posterior gastric stromal tumors. Surg Endosc 2000;14:349-53.

14. Binmoeller KF, Grimm H, Soehendra N. Endoscopic closure of a perforation using metallic clips after snare excision of a gastric leiomyoma. Gastrointest Endosc 1993;39:172-4.

15. Chang KJ, Yoshinaka R, Nguyen P. Endoscopic ultrasound assisted band ligation: A new technique for resection of submucosal tumors. Gastrointest Endosc 1996;44:720-2.

16. Sun S, Wang M, Sun S. Use of endoscopic ultrasound-guided injection in endoscopic resection of solid submucosal tumors. Endoscopy 2002;34:82-5.

17. Crosta C, Meroni E, Alloni R, Botti F, Carrara A, Taschieri AM. Gastric submucosal neoplasms: New diagnostic and therapeutic procedures. Ital J Surg Sci 1987;17:131-4.

18. Yu JP, Luo HS, Wang XZ. Endoscopic treatment of submucosal lesions of the gastrointestinal tract. Endoscopy 1992;24:190-3.

19. Spinelli P, Cerrai FG, Cambareri AR, Meroni E, Pizzetti P. Two-step endoscopic resection of gastric leiomyomas. Surg Endosc 1993;7:90-2.

20. Sun S, Jin Y, Chang G, Wang C, Li X, Wang Z. Endoscopic band ligation without electrosurgery: A new technique for excision of small upper-GI leiomyoma. Gastrointest Endosc 2004;60:218-22.

21. Kawamoto K, Yamada Y, Furukawa N, et al. Endoscopic submucosaltumorectomy for gastrointestinal submucosal tumors restricted to the submucosa: A new form of endoscopic minimal surgery. Gastrointest Endosc 1997;46:311-7.

22. Hosokawa K, Yoshida S. Recent advances in endoscopic mucosal resection for early gastric cancer [in Japanese with English abstract]. Gan To Kagaku Ryoho 1998;25:476-83.

23. Hamouda AH, Chisholm E. Endoscopic alcohol injection as a treatment modality for oesophageal leiomyoma. Eur J Surg Oncol 2008;34:122-4. 


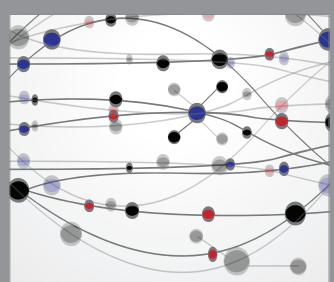

The Scientific World Journal
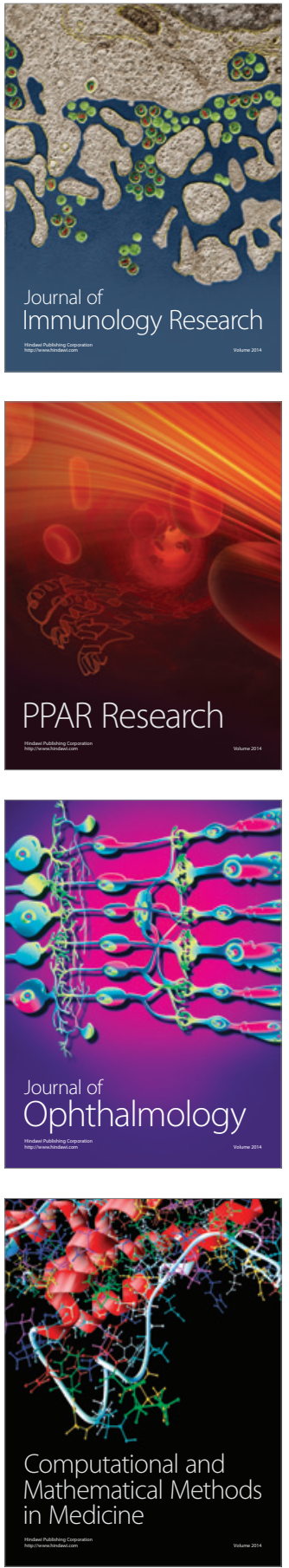

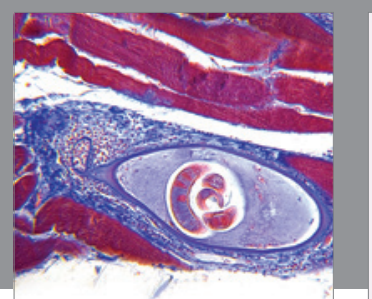

Gastroenterology Research and Practice

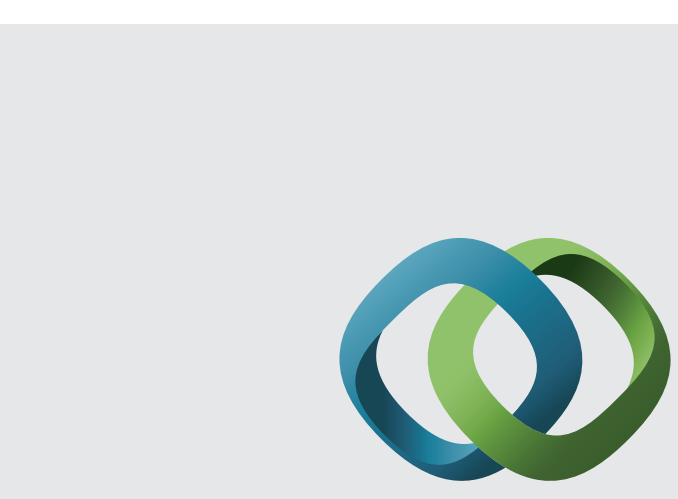

\section{Hindawi}

Submit your manuscripts at

http://www.hindawi.com
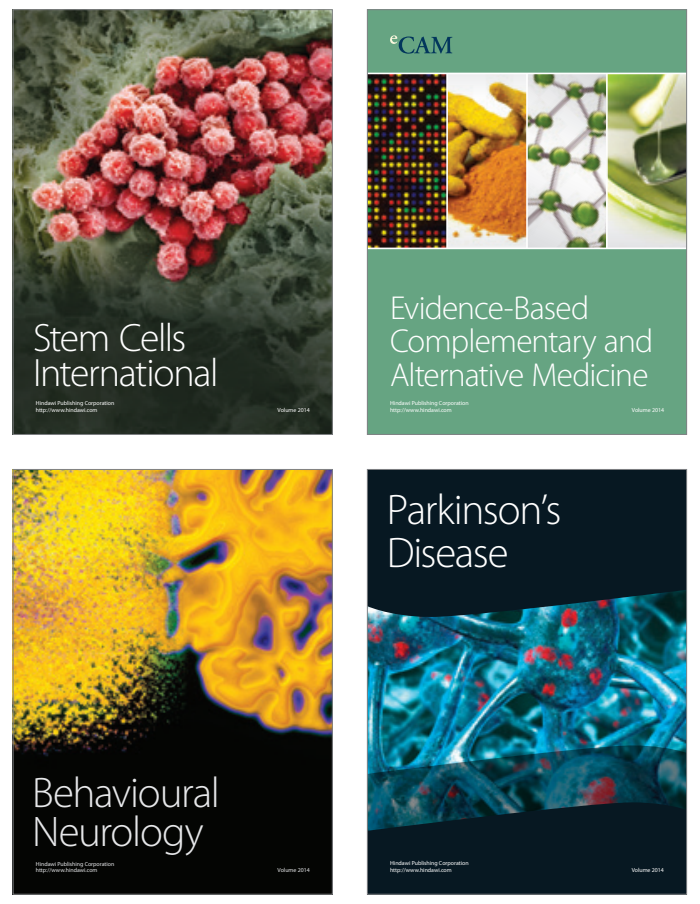
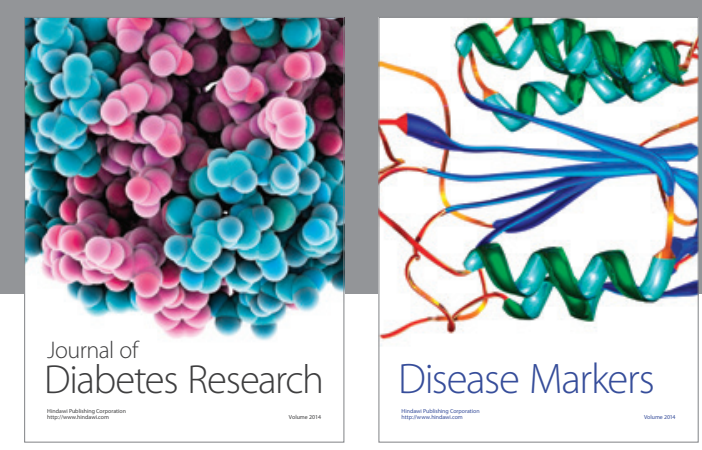

Disease Markers
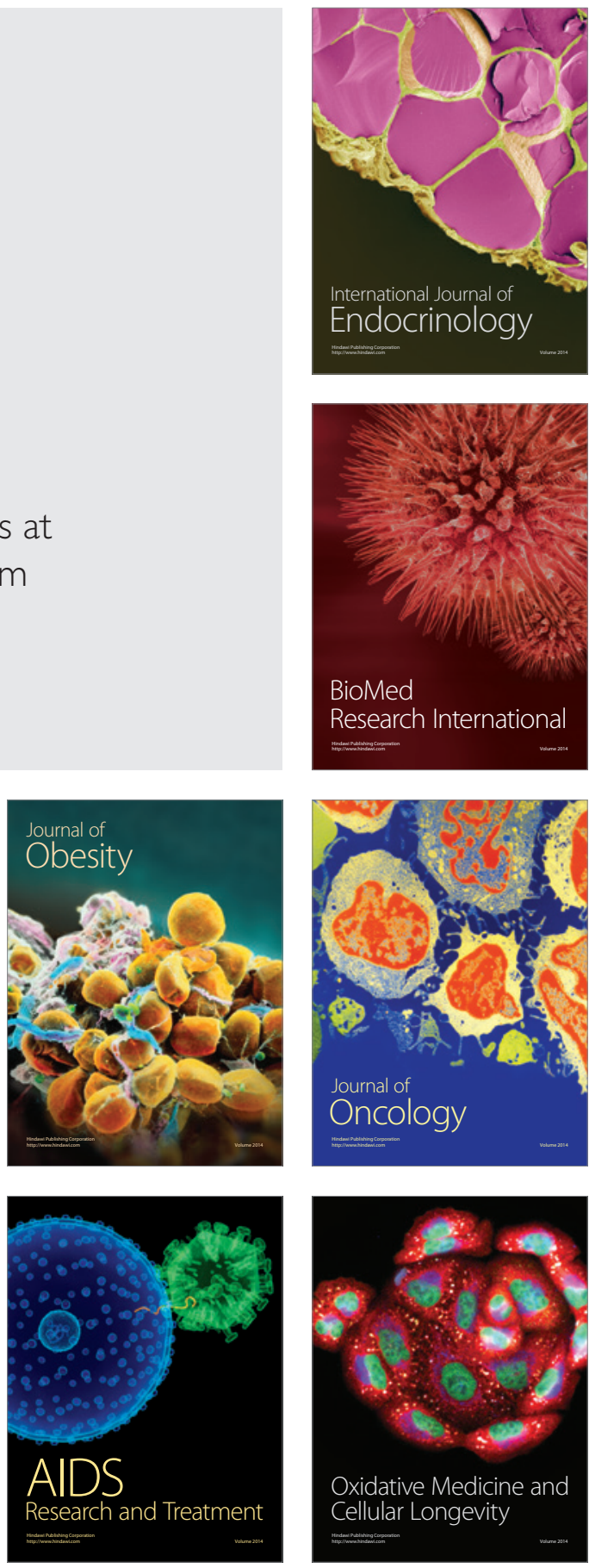